\title{
Occupational and nonoccupational factors associated with high grade bronchial pre-invasive lesions
}

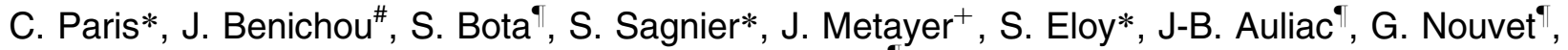 \\ L. Thiberville
}

Occupational and nonoccupational factors associated with high grade bronchial preinvasive lesions. C) ERS Journals Ltd 2003.

ABSTRACT: Besides tobacco exposure, factors associated with the development of pre-invasive bronchial lesions are not known. Autofluorescence bronchoscopy was used to assess the prevalence of severe dysplasia and carcinoma in situ (SD/CIS) of the proximal bronchial tree in relation to occupational or nonoccupational carcinogen exposure.

Among the 241 individuals in this study, the overall prevalence of at least one SD/CIS was 9\% (21 subjects). Multivariable analysis revealed significant and independent associations between presence of SD/CIS and: 1) active smoking, relative to former smokers; 2) presence of synchronous invasive lung cancer; 3) duration of asbestos exposure and; 4) exposure to other occupational carcinogens.

The independent associations of synchronous lung cancer with severe dysplasia and carcinoma, after adjusting for both occupational and nonoccupational carcinogen exposures, suggest other mechanisms than a field cancerisation may be involved in the carcinogenesis of these pre-invasive lesions. Moreover, active smokers, patients with recently resected invasive lung cancer and workers occupationally exposed to bronchial carcinogens may represent a population of choice for early cancer endoscopic detection programmes in view of their high severe dysplasia and carcinoma prevalence. Eur Respir J 2003; 21: 332-341.

Lung cancer is one of the most frequent malignancies in both males and females [1]. Prevalence estimates were $\sim 180,000$ cases among males in the USA in 1998. Five-yr survival from lung cancer is $<15 \%$ in the USA and most European countries, and worse in developing countries.

To date, diagnosis and surgical resection of lung cancer at an early stage is considered to be effective, based on dramatically improved survival rates for resected subjects compared to subjects with no surgery [2]. However, only a minority of subjects are diagnosed at a resectable stage, because of the limitations of standard radiographical techniques and the lack of specific symptoms in early stages of the disease. Randomised trials assessing periodic chest radiography and sputum cytology to screen for lung cancer in high risk individuals have failed to show a decrease in the specific mortality rate from lung cancer in the screened population [3].

Several techniques have recently been developed in an effort to more effectively detect lung cancer at an early stage [2], including imaging of pulmonary nodules by low-dose spiral computer tomography (CT) scan, quantitative microscopy on sputum cells or molecular assays in bronchoalveolar lavage fluid. Although these techniques are currently under assessment, early results are promising.

\begin{abstract}
Depts of *Occupational Diseases, \#Biostatistics, "Pneumology and the ${ }^{+}$Pathology Laboratory, Rouen University Hospital, Rouen, France.
\end{abstract}

Correspondence: C. Paris, Occupational Diseases Dept, Rouen University Hospital, 1 rue de Germont, 76031, Rouen Cedex, France.

Fax: 33232888184

E-mail: christophe.paris@chu-rouen.fr

Keywords: Asbestos, bronchoscopy, lung neoplasms, occupational exposure

Received: January 12002

Accepted after revision: September 30 2002

This research was supported by a "Programme Hospitalier de Recherche Clinique" grant from the French Ministry of Research (1996).
Nonsmall cell lung cancer and particularly squamous cell cancer is thought to be preceded by a period ranging from 6 months to several years [4], characterised by the progression from pre-invasive lesions to invasive cancer. This hypothesis is supported by recent follow-up data from the authors' group and others suggesting a true invasive neoplastic potential for at least bronchial carcinoma in situ (CIS) and possibly severe dysplasia $[5,6]$. Thus, a promising approach would be to detect and treat these early intra-epithelial lesions in the bronchial tree of highrisk individuals. Several observational studies [7-10] as well as a recent randomised trial [11] have shown an increased sensitivity of autofluorescence bronchoscopy to detect such pre-invasive lesions relative to white light endoscopy. The question is now open to debate as to whether or not subjects at high risk for lung cancer should undergo early detection bronchoscopy at regular intervals, as is recommended for patients with familial adenomatous polyposis using colonoscopy. Implementation of this strategy implies a better knowledge of the factors that are associated with the development of precancerous and pre-invasive lesions in the proximal bronchi. This is regarded as one of the main challenges in lung cancer screening [12].

Criteria for selection of individuals at high-risk 
for invasive lung cancer were proposed by the International Association for the Study of Lung Cancer in 1995 [13]. These criteria include a personal history of resected nonsmall cell carcinoma, head or neck tumour; long-time survival from small-cell carcinoma; occupational exposure to asbestos or other respiratory occupational carcinogens; smoking; family history of bronchial neoplasia; current chronic obstructive lung disease and genetic polymorphisms suspected to be involved in the detoxification of tobacco smoke carcinogens.

To date, reported risk factors for bronchial preinvasive lesions are mainly related to current or previous tobacco exposure [7-11]. No results are available regarding the risk of developing pre-invasive lesions in relation with other risk factors of invasive lung cancer such as asbestos exposure.

An Early Detection Study was conducted using fluorescence endoscopy in individuals at high-risk of developing lung cancer because of their smoking or occupational exposure to asbestos. The aim of this study was to help better identify the most suitable high risk population that would be a candidate for early endoscopic detection. For this purpose, the prevalence of high grade pre-invasive bronchial lesions in relation with occupational and nonoccupational exposures was assessed.

\section{Materials and methods}

The Early Detection Study presented here is part of the Early Lung Cancer Detection Programme, which was initiated at Rouen University Hospital, France in 1995. In this programme, individuals at high risk of developing lung cancer were submitted periodically to fluorescence fibreoptic endoscopy in order to detect early lung cancer and pre-invasive lesions in their proximal bronchial tree. At the time of their first baseline endoscopy, subjects were systematically assessed for occupational as well as nonoccupational lung cancer risk factors using a standardised questionnaire. The current report only deals with data from this baseline assessment.

\section{Eligibility criteria for the early lung cancer detection programme}

To be eligible, subjects had to have a personal history of treated lung, laryngeal or oesophageal cancer, a minimum of past or current smoking exposure of 30 pack-yrs of cigarettes, or a significant exposure to occupational respiratory carcinogens, conditions known to increase the risk of lung cancer. The study was approved by the Regional Ethical Committee on Human Research and all subjects were asked to provide informed consent.

\section{Endoscopy}

White light and fluorescence bronchoscopy examination was performed under local anaesthesia using the Lung Imaging Fluorescence Endoscope (LIFE System, Xillix Technology Corp., Richmond, B.C., Canada) in the Dept of Pneumology. During the procedure, all bronchial areas with suspected metaplasia, dysplasia or cancer under white light or fluorescence examination were biopsied and sampled for pathological examination.

\section{Histological evaluation of the bronchial biopsy specimens}

Bronchial biopsy specimens were reviewed jointly by two pathologists according to the World Health Organisation (WHO) 1998 criteria for pre-invasive bronchial lesions [14]. The pathological analysis was blinded to risk factor assessment data. All specimens were classified into three groups, as follows: Group I: normal or inflammatory, i.e. reserve cell hyperplasia, regular metaplasia or mild dysplasia; Group II: moderate dysplasia; Group III: severe dysplasia or CIS.

\section{Risk factor assessment}

For all subjects, an interview was conducted by two experienced physicians in order to assess risk factors. Interviews were conducted without knowledge of the pathology results. Tobacco consumption data recorded in the questionnaire included the following: duration of tobacco exposure in years; number of cigarettes smoked per day; and, for former smokers, time since cessation of smoking. Subjects who had not smoked $\geqslant 1$ cigarette per day in the year before the baseline bronchial examination was performed were considered as former smokers.

A standardised questionnaire based on a previously published study [15] was used to collect information on work history, namely history of all jobs held for $\geqslant 6$ months and detailed description of the tasks performed by the subjects. For each job, specific questions related to known asbestos exposure tasks were asked. Asbestos and other occupational carcinogen exposure were assessed by the same expert, blinded both to the patient's smoking status and pathology results. Probability of asbestos exposure (no exposure, possible and definite exposure) and quantification of its duration (in years) were determined according to the description of tasks for each job period. Quantification of the level of asbestos exposure was based on specific data on factories and industrial processes when available, or on the French Asbestos Specific Job Exposure Matrix EVALUTIL [16]. For the other respiratory carcinogens, i.e., silica, polycyclic aromatic hydrocarbons, nickel and chrome salts or other known human bronchial carcinogens belonging to group I as defined by the International Agency Research on Cancer [17], only the presence or absence of definite exposure for $>10$ yrs were distinguished.

History of lung or ear, nose and throat (ENT) cancer was recorded as synchronous if the tumour had been treated in the year prior to the baseline bronchoscopy examination, or in the presence of an invasive lung tumour at baseline, if developed in another 
bronchus than the pre-invasive lesion. Conversely, the cancer was considered as cured in subjects having achieved a complete response to treatment for $\geqslant 1 \mathrm{yr}$.

\section{Patient classification according to pre-invasive lesions}

Subjects were classified according to the highest grade noninvasive lesion that could be sampled during the baseline fluorescence endoscopy, independently of the number of other pre-invasive lesions observed in their bronchial tree.

\section{Statistical analysis}

Descriptive statistics were used for the distribution of general characteristics, medical history, tobacco consumption, occupational exposure to carcinogens and highest grade pre-invasive bronchial lesions.

In order to assess the association between the grade of pre-invasive lesions (group I, II or III) and occupational and nonoccupational exposure, Chi-squared homogeneity test or Fisher's exact test were used when the sample size was too small. Odds ratios (ORs) and corresponding 95\% confidence intervals (CIs) were estimated for the presence of high grade preinvasive lesions (i.e., group III lesions) versus all lower grade lesions (i.e., group I and II lesions) and Cochran's trend test, or an exact version of it, was used when applicable.

In order to identify factors independently associated with the presence of high grade pre-invasive lesions, unconditional logistical regression with backward stepwise selection of variables was used.

From the final model that included four factors, predicted probabilities and their 95\% CIs for the presence of high grade pre-invasive lesions were estimated for all combinations of these factors. The logit transformation was used to estimate 95\% CIs. These predicted probabilities would apply to subjects with the same distribution of exposure factors for the detection of high grade lesions by a single autofluorescence endoscopy procedure.

No high grade pre-invasive lesions were present among nonsmokers. For the sake of consistency, nonsmokers $(n=13)$ were excluded from all uni and multivariable analyses assessing the association between the grade of pre-invasive lesions and occupational and nonoccupational exposure. For all results, two sided $\mathrm{p}$-values are given and were considered significant when $\mathrm{p}<0.05$.

\section{Results}

\section{Subjects characteristics}

Two hundred and forty-one subjects including 13 nonsmokers, recruited from February 1995 to June 2000 , were subjected to the detailed risk factor questionnaire and had a baseline fluorescence endoscopy. Overall, 1,500 biopsies were performed, from which the highest grade pre-invasive lesion was determined for each subject. Table 1 displays the distributions of age, sex, smoking status, personal history of lung and ENT cancer and occupational lung carcinogen exposure at baseline assessment. Overall, the mean age was $57.7 \pm 9.9$ yrs (mean \pm sD) and $90 \%$ of subjects were male. Among them, 146 subjects $(61 \%)$ had been occupationally exposed to asbestos, $31(13 \%)$ to other occupational carcinogens, $228(95 \%)$ to tobacco including 147 current smokers $(61 \%)$ and 81 exsmokers $(34 \%)$, and $128(56 \%)$ had a cumulative smoking history of $\geqslant 40$ pack-yrs. Twenty-five subjects $(10 \%)$ presented with a history of cured lung cancer, 15 subjects $(6 \%)$ with cured ENT cancer and 24 subjects $(10 \%)$ with synchronous lung cancer, of whom seven had micro-invasive bronchial cancer. Six (2\%) subjects had synchronous ENT cancer.

\section{Pre-invasive status according to nonoccupational exposure (univariable analysis)}

Altogether, 21 subjects ( $9 \%$ ) presented high grade pre-invasive lesions including nine with severe dysplasia and 12 with CIS. Most of them were current or former smokers so that the 13 nonsmokers were not included in any of the analyses presented in the remaining part of the results section. Age was slightly

Table 1.-Baseline characteristics of the 241 subjects in the early detection study

\begin{tabular}{lr}
\hline Characteristics & Total \\
\hline Age mean \pm SD & $57.7 \pm 9.9$ \\
Sex & $218(90)$ \\
Male & $23(10)$ \\
Female & \\
Personal history of lung cancer & $192(80)$ \\
No history of lung cancer & $25(10)$ \\
Cured invasive lung cancer & \\
Synchronous invasive lung cancer & $24(10)$ \\
Personal history of ENT cancer & \\
No history of ENT cancer & $220(92)$ \\
Cured ENT cancer & $15(6)$ \\
Synchronous invasive ENT cancer & \\
Smoking status & $6(2)$ \\
Nonsmokers & $13(5)$ \\
Former smokers & $81(34)$ \\
Current smokers & $147(61)$ \\
No. cigarettes per day $\geqslant 20^{\S}$ & $185(81)$ \\
Duration of smoking $\geqslant 20$ yrs & \\
No. of pack-yrs $\geqslant 40^{\S}$ & $215(94)$ \\
Delay since quitting smoking $\geqslant 10 \mathrm{yrs}^{f}$ & $128(56)$ \\
Asbestos exposure present & $39(48)$ \\
Duration of asbestos exposure $\geqslant 20 \mathrm{yrs}^{\# \#}$ & $146(61)$ \\
Latency of asbestos exposure $\geqslant 20 \mathrm{yrs}^{\# \#}$ & $62(42)$ \\
Delay since the end of asbestos & $137(94)$ \\
exposure $\geqslant 10$ yrs & $99(68)$ \\
Others occupational exposure present & \\
\hline Data are presented as & $31(13)$ \\
\hline
\end{tabular}

Data are presented as n (\%) unless otherwise stated. ${ }^{\#}$ : No clinical activity, treatment stopped for at least $1 \mathrm{yr}$; presence of invasive cancer at bronchoscopy or cancer treated in the previous year; ${ }^{+}:$ear, nose and throat (ENT) cancer treated in the previous year; ${ }^{\$}$ : among current and former smokers only $(\mathrm{n}=228) ;{ }^{f}$ : among former smokers only $(\mathrm{n}=81){ }^{\# \#}$ : among subjects ever exposed to asbestos $(\mathrm{n}=146)$. 
higher among patients with high grade pre-invasive lesions, albeit this difference was not significant (59.0 versus $57.5 \mathrm{yrs}, \mathrm{p}=0.493$, unpaired t-test). Presence of high grade pre-invasive lesions was not associated with sex (OR 1.0, 95\% CI 0.2-4.5 for females). Figures 1 and 2 display the distribution of smoking and personal history of lung or ENT cancer according to the grade of pre-invasive bronchial lesions (groups I, II, III). Table 2 provides corresponding ORs and $95 \%$ CIs for high grade pre-invasive lesions (group III) relative to all lower grade lesions combined (groups I-II). Current smokers had significantly higher grade lesions than former smokers $(\mathrm{p}=0.002)$. Indeed, 18 subjects out of $21(86 \%)$ with high grade lesions were current smokers (i.e. a 12\% prevalence of high grade lesions among current smokers), while three were former smokers (i.e. a 4\% prevalence of high grade lesions). The OR for high grade pre-invasive lesions was $3.6(95 \%$ CI $1.0-12.7)$ for current smokers relative to former smokers. Significant associations were found between grade severity (I, II, III) and number of cigarettes per day, number of pack-yrs and delay since quitting smoking (fig. 1). Moreover, the prevalence of high-grade pre-invasive lesions significantly decreases

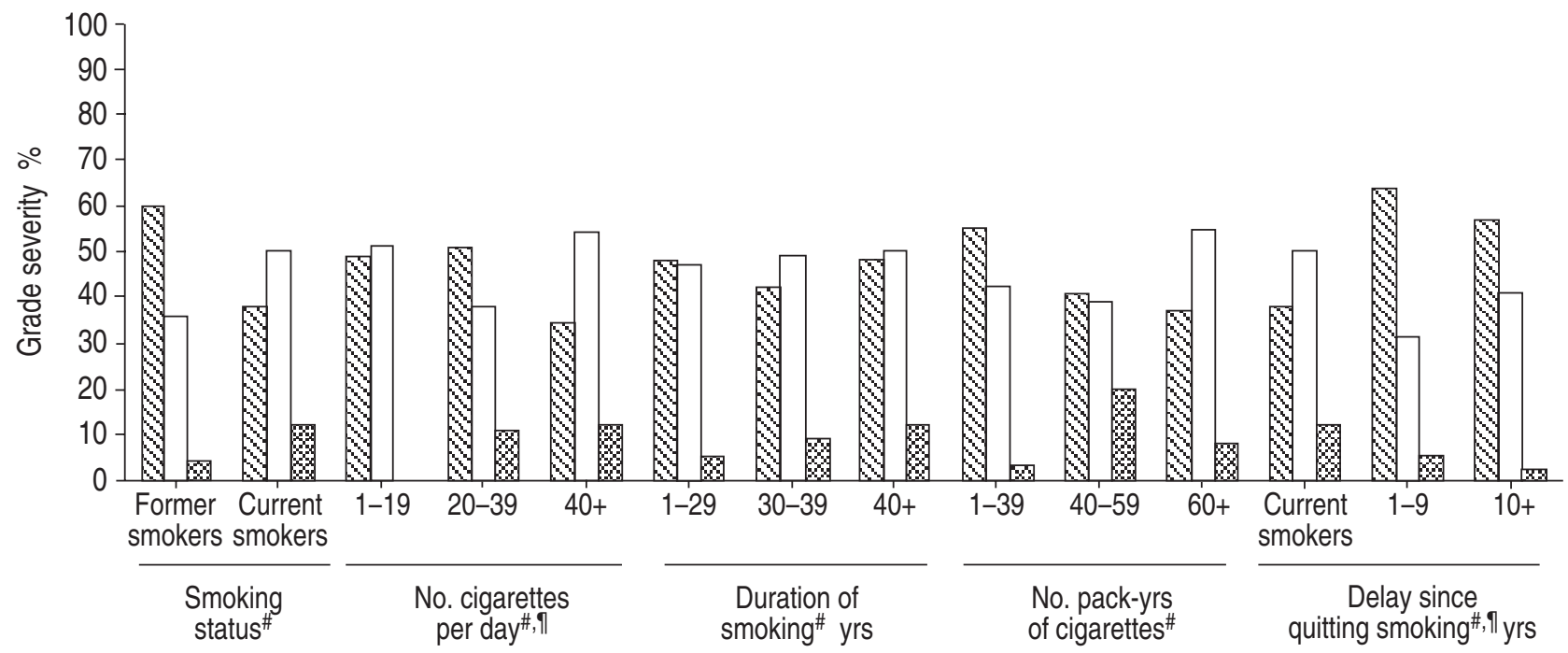

Fig. 1.-Distribution of grade severity ( $\mathbb{\$}$ : mild dysplasia or lower grade; $\square$ : moderate dysplasia; $\mathbf{0}$ : severe dysplasia or carcinoma in situ) according to smoking status. Thirteen subjects who never smoked are not included (five with at most mild dysplasia, eight with moderate dysplasia). ${ }^{\#}$ : p-values based on Chi-squared or Fisher's exact test; ': exact test was performed due to small sample size. Smoking status: $\mathrm{p}=0.002$; no. cigarettes per day: $\mathrm{p}=0.018$; duration of smoking: $\mathrm{p}=0.498$; no. pack yrs of cigarettes: $\mathrm{p}=0.002$; delay since quitting smoking: $\mathrm{p}=0.013$.

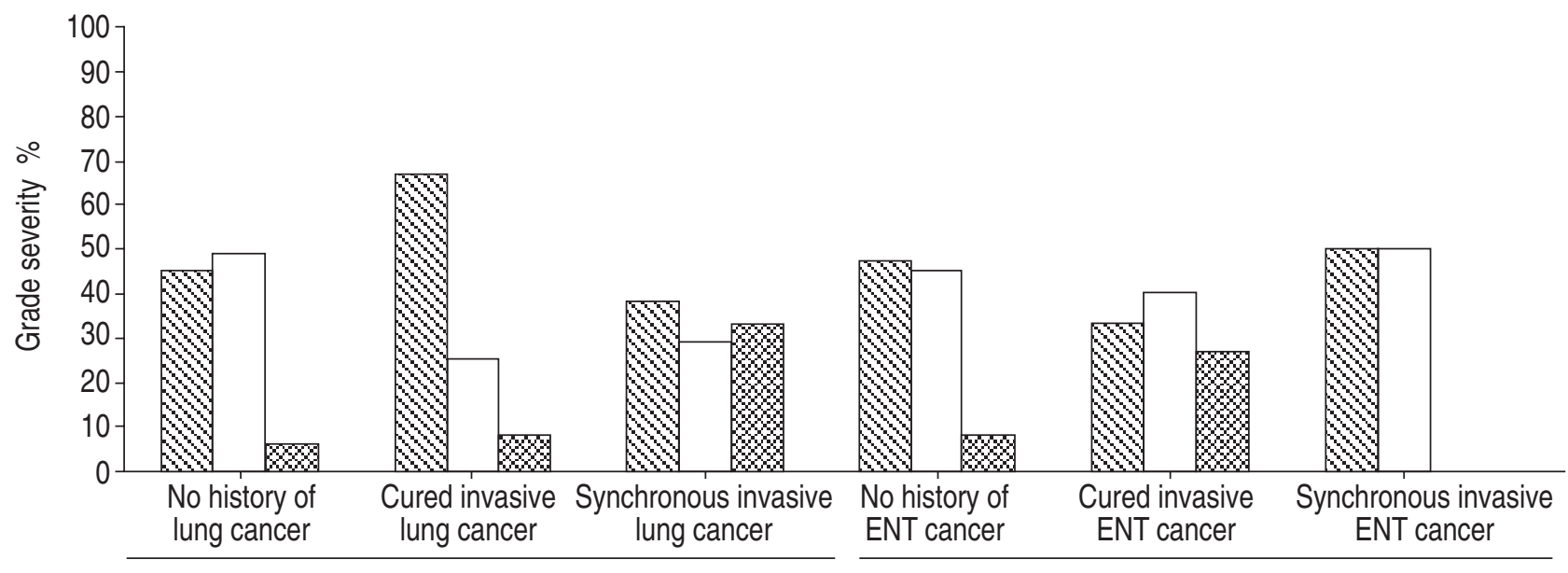

Personal history of lung cancer

Personal history of ENT cancer

Fig. 2. - Distribution of grade severity ( $\mathbb{\mathbb { N }}$ : mild dysplasia or lower grade; $\square$ : moderate dysplasia; $\mathbf{\mathbf { Q }}$ : severe dysplasia or carcinoma in situ) according to personal history of lung or ear, nose or throat (ENT) cancer. Thirteen subjects who never smoked are not included (five with at most mild dysplasia, eight with moderate dysplasia). For personal history of lung cancer and ENT cancer there was no clinical activity, and treatment had been stopped for $\geqslant 1 \mathrm{yr}$. For personal history of lung cancer presence of invasive lung cancer at bronchoscopy or cancer treated in the previous year. ENT cancer treated in the previous year. p-Values were based on chi-squared or Fisher's exact test. Personal history of lung cancer: $\mathrm{p}=0.001$; personal history of ENT cancer: $\mathrm{p}=0.024$. 
Table 2. - Nonoccupational characteristics for high grade pre-invasive lesions (severe dysplasia or carcinoma in situ) relative to all lower grade lesions combined in 228 subjects in the early detection study

\begin{tabular}{|c|c|c|c|}
\hline Nonoccupational characteristics & $\begin{array}{l}\text { No. subjects without/with } \\
\text { high grade pre-invasive } \\
\text { lesions }\end{array}$ & $\begin{array}{c}\text { OR and p-value for } \\
\text { Cochran's trend test when } \\
\text { applicable }\end{array}$ & $95 \% \mathrm{CI}$ \\
\hline \multicolumn{4}{|l|}{ Smoking status } \\
\hline Former smokers & $78 / 3$ & 1.0 & \\
\hline Current smokers & $129 / 18$ & 3.6 & $1.0-12.7$ \\
\hline \multicolumn{4}{|l|}{ No. cigarettes per day } \\
\hline$\leqslant 40$ & $155 / 14$ & 1.0 & \\
\hline$\geqslant 40$ & $52 / 7$ & 1.1 & $0.4-2.8$ \\
\hline \multicolumn{4}{|l|}{ Duration of smoking yrs } \\
\hline$\leqslant 29$ & $57 / 3$ & 1.0 & \\
\hline $30-39$ & $73 / 7$ & 1.8 & $0.5-7.3$ \\
\hline$\geqslant 40$ & $77 / 11$ & $\begin{array}{c}2.7 \\
\mathrm{p}=0.120\end{array}$ & $0.7-10.2$ \\
\hline \multicolumn{4}{|l|}{ No. pack-yrs of cigarettes } \\
\hline$\leqslant 39$ & $97 / 3$ & 1.0 & \\
\hline $40-59$ & $53 / 13$ & 7.9 & $2.2-29.0$ \\
\hline$\geqslant 60$ & $57 / 5$ & $\begin{array}{c}2.8 \\
\mathrm{p}=0.128\end{array}$ & $0.7-12.3$ \\
\hline \multicolumn{4}{|l|}{ Delay since quitting smoking yrs } \\
\hline$\geqslant 10$ & $41 / 1$ & 1.0 & \\
\hline $1-9$ & $37 / 2$ & 2.2 & $0.2-25.4$ \\
\hline Current smokers or $<1 \mathrm{yr}$ & $129 / 18$ & $\begin{array}{c}5.7 \\
\mathrm{p}=0.031^{\oplus}\end{array}$ & $0.7-44.1$ \\
\hline \multicolumn{4}{|l|}{ Personal history of lung cancer } \\
\hline No history of lung cancer & $169 / 11$ & 1.0 & \\
\hline Cured invasive lung cancer ${ }^{\S}$ & $22 / 2$ & 1.4 & $0.3-6.7$ \\
\hline Synchronous invasive lung cancer ${ }^{+}$ & $16 / 8$ & $\begin{array}{c}7.7 \\
\mathrm{p}<0.001^{\bullet}\end{array}$ & $2.7-21.8$ \\
\hline \multicolumn{4}{|l|}{ Personal history of ENT cancer } \\
\hline No history of ENT cancer & 190/17 & 1.0 & \\
\hline Cured ENT cancer ${ }^{\S}$ & $11 / 4$ & 4.0 & $1.2-14.1$ \\
\hline Synchronous invasive ENT cancer ${ }^{f}$ & $6 / 0$ & $\mathrm{NA}^{\# \#}$ & \\
\hline
\end{tabular}

Thirteen subjects who never smoked are not included (five with at most mild dysplasia, eight with moderate dysplasia). ${ }^{\top}$ : exact test was performed due to small sample size; ${ }^{\S}$ : no clinical activity, treatment stopped for $\geqslant 1 \mathrm{yr} ;{ }^{+}$: presence of invasive cancer at bronchoscopy or cancer treated in the previous year; ${ }^{f}$ : ear, nose and throat (ENT) cancer treated in the previous year; ${ }^{\# \#}$ : nonestimable odds ratio (OR) because no high grade pre-invasive lesions were observed among these subjects. CI: confidence interval.

with the delay since quitting smoking $(\mathrm{p}=0.031$, trend test, table 2) and showed a nonsignificant increase with duration of smoking ( $\mathrm{p}=0.120$, trend test, table 2).

Overall, a strong association was found between personal history of lung cancer and the severity of preinvasive lesions ( $\mathrm{p}=0.001$, fig. 2). Relative to subjects with no personal history of lung cancer, the OR for high grade pre-invasive lesions (table 2) was significantly elevated in subjects with synchronous lung cancer (OR 7.7, 95\% CI 2.7-21.8), but not in subjects with cured lung cancer (OR 1.4, 95\% CI 0.3-6.7). A significant association was found between the presence of high grade lesions and a history of cured ENT cancer (OR 4.0, 95\% CI 1.2-14.1).

Pre-invasive status according to occupational exposure (univariable analysis)

Figure 3 displays the distribution of occupational exposure variables according to the grade of pre-invasive bronchial lesions whereas table 3 provides corresponding ORs. Among the 146 subjects (64\% of all subjects) occupationally exposed to asbestos, duration of exposure was $\geqslant 20 \mathrm{yrs}$ in 56 subjects $(38 \%)$ and latency (i.e., time elapsed from the first exposure to asbestos) was $>30 \mathrm{yrs}$ in 103 of them $(71 \%)$ and $<20$ yrs in only nine $(6 \%)$.

Overall, there was a significant association between the severity of pre-invasive lesions and asbestos exposure ( $\mathrm{p}=0.037$, fig. 3 ). The OR for high grade preinvasive lesions (table 3) was significantly elevated (OR 4.5, 95\% CI 1.3-15.8) among subjects ever exposed to asbestos. Moreover, there was a significant increase in the OR for high grade lesions with the following: 1) duration of asbestos exposure (OR 3.3 and 6.5 for $1-19$ and 20+ yrs respectively, relative to no exposure); 2) delay since last exposure to asbestos (OR 3.2 and 7.9 for $10+$ and $<10$ yrs respectively, relative to no exposure); and 3) latency for asbestos exposure (OR 3.7 and 5.8 for 1-39 and $40+$ yrs respectively, relative to no exposure). Exposure to other occupational carcinogens occurred in 29 subjects overall (13\% of all subjects). A significant elevation in the OR for high grade pre-invasive lesions was found among subjects exposed to other occupational carcinogens such as silica and polycyclic aromatic hydrocarbons (OR 3.2, 95\% CI 1.1-9.0). 


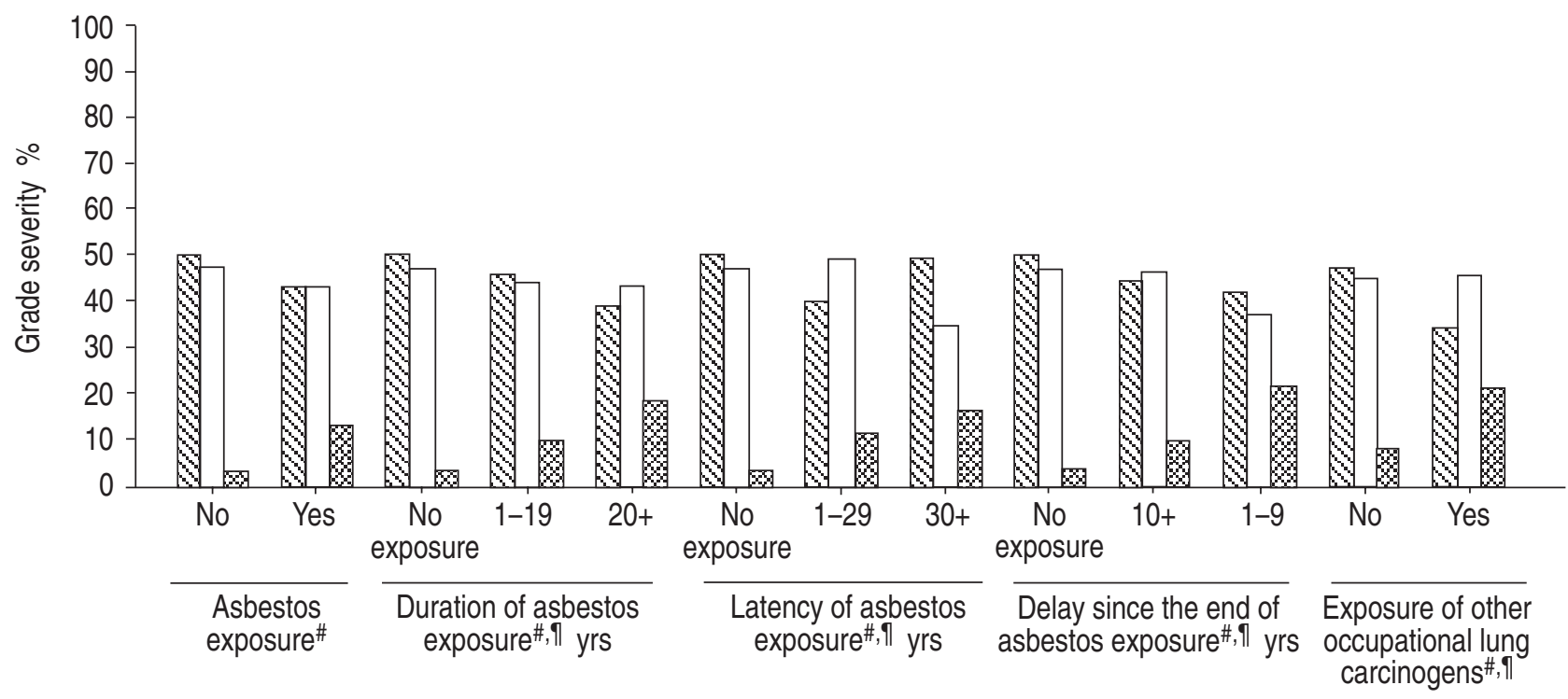

Fig. 3. - Distribution of grade severity ( $\mathbb{\$}$ : mild dysplasia or lower grade; $\square$ : moderate dysplasia; $\mathbf{E}$ : severe dysplasia or carcinoma in situ) according to occupational exposure. Thirteen subjects who never smoked are not included (five with at most mild dysplasia, eight with moderate dysplasia). \#: p-values based on Chi-squared or Fisher's exact test; ": exact test was performed due to small sample size. Asbestos exposure: $\mathrm{p}=0.037$; duration of asbestos exposure: $\mathrm{p}=0.057$; latency of asbestos exposure: $\mathrm{p}=0.043$; delay since the end of asbestos exposure: $\mathrm{p}=0.031$; exposure to other occupational lung carcinogens: $\mathrm{p}=0.066$.

Pre-invasive status according to occupational and nonoccupational exposure (multivariable analysis)

Occupational and nonoccupational factors independently associated with the presence of high grade pre-invasive lesions were selected through backward stepwise unconditional logistic regression (table 4).
Results from multivariable analysis essentially confirmed results from univariable analysis with some differences. Two potent variables appeared as independently associated with the presence of high grade lesions, namely the presence of synchronous invasive bronchial cancer (OR 11.7, 95\% CI 3.1-43.4, $\mathrm{p}=0.001$ ) and active smoking (OR 6.7, 95\% CI 1.5-29.4, $\mathrm{p}=0.012$ ).

Table 3. - Occupational exposure characteristics for high grade pre-invasive lesions (severe dysplasia or carcinoma in situ) relative to all lower grade lesions combined in 228 subjects in the early detection study

\begin{tabular}{lcc}
\hline Occupational exposure characteristics & $\begin{array}{c}\text { No. subjects } \\
\text { without/with } \\
\text { high grade }\end{array}$ & $\begin{array}{c}\text { OR and } \\
\text { p-value for } \\
\text { Cochran's trend } \\
\text { pre-invasive lesions } \\
\text { test when applicable }\end{array}$ \\
\hline
\end{tabular}

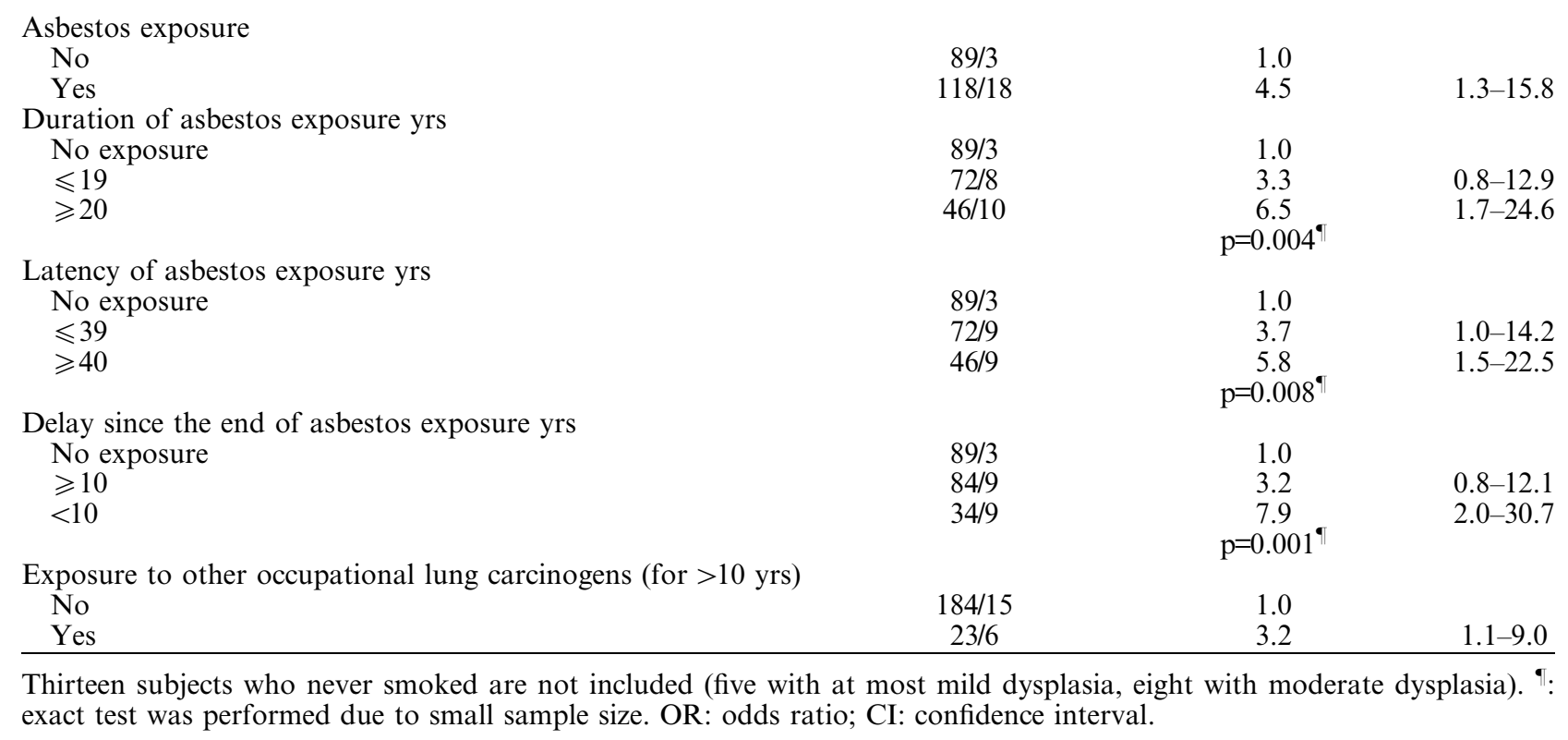


Table 5. - Predicted probabilities (95\% confidence intervals ${ }^{\#}$ ) of carrying high grade pre-invasive lesions for selected combinations of occupational and nonoccupational factors as calculated from the logistic model in table 4

\begin{tabular}{|c|c|c|c|c|c|c|c|c|}
\hline & \multicolumn{4}{|c|}{ Former smokers } & \multicolumn{4}{|c|}{ Current smokers } \\
\hline & \multicolumn{2}{|c|}{$\begin{array}{l}\text { No asbestos exposure } \\
\text { and exposure to } \\
\text { other occupational } \\
\text { carcinogens: }\end{array}$} & \multicolumn{2}{|c|}{$\begin{array}{l}\text { Asbestos exposure } \geqslant 20 \text { yrs } \\
\text { and exposure to other } \\
\text { occupational carcinogens: }\end{array}$} & \multicolumn{2}{|c|}{$\begin{array}{l}\text { No asbestos exposure } \\
\text { and exposure to } \\
\text { other occupational } \\
\text { carcinogens: }\end{array}$} & \multicolumn{2}{|c|}{$\begin{array}{l}\text { Asbestos exposure } \geqslant 20 \text { yrs } \\
\text { and exposure to other } \\
\text { occupational carcinogens: }\end{array}$} \\
\hline & $<10$ yrs & $\geqslant 10 \mathrm{yrs}$ & $<10 \mathrm{yrs}$ & $\geqslant 10 \mathrm{yrs}$ & $<10 \mathrm{yrs}$ & $\geqslant 10 \mathrm{yrs}$ & $<10$ yrs & $\geqslant 10 \mathrm{yrs}$ \\
\hline \multicolumn{9}{|l|}{$\begin{array}{l}\text { Personal history } \\
\text { of invasive } \\
\text { lung cancer } \\
\text { no history }\end{array}$} \\
\hline no history & $\begin{array}{c}0.002 \\
(0.000-0.018)\end{array}$ & $\begin{array}{c}0.013 \\
(0.002-0.097)\end{array}$ & $\begin{array}{c}0.021 \\
(0.005-0.094)\end{array}$ & $\begin{array}{c}0.107 \\
(0.020-0.419)\end{array}$ & $\begin{array}{c}0.015 \\
(0.004-0.060)\end{array}$ & $\begin{array}{c}0.077 \\
(0.017-0.291)\end{array}$ & $\begin{array}{c}0.122 \\
(0.051-0.267)\end{array}$ & $\begin{array}{c}0.433 \\
(0.157-0.759)\end{array}$ \\
\hline $\begin{array}{l}\text { invasive lung } \\
\text { cancer }\end{array}$ & $\begin{array}{c}0.028 \\
(0.005-0.158)\end{array}$ & $\begin{array}{c}0.138 \\
(0.021-0.547)\end{array}$ & $\begin{array}{c}0.212 \\
(0.058-0.539)\end{array}$ & $\begin{array}{c}0.596 \\
(0.190-0.903)\end{array}$ & $\begin{array}{c}0.157 \\
(0.043-434)\end{array}$ & $\begin{array}{c}0.505 \\
(0.156-0.850)\end{array}$ & $\begin{array}{c}0.631 \\
(0.345-0.848)\end{array}$ & $\begin{array}{c}0.904 \\
(0.630-0.982)\end{array}$ \\
\hline
\end{tabular}

\#: Based on the logit transformation; " presence of invasive lung cancer at bronchoscopy or cancer treated in the previous year.

extensive definition of CIS used by AuERBACH et al. [18] including "all lesions composed entirely of atypical cells without cilia present". The findings of the present study, based on a more recent and restrictive definition of CIS [14], are consistent with prevalences of high grade lesions reported by LAM and co-workers $[7,19]$ and other groups using fluorescence endoscopy $[8,10,11]$, and seem more compatible with the invasive neoplastic potential for the majority of CIS lesions.

Asbestos is a well-known occupational carcinogenic agent that has been consistently found to be associated with lung cancer in epidemiological studies. The current study provides the first assessment of asbestos exposure as a risk factor for proximal bronchial preinvasive lesions, showing a four-fold higher prevalence of high grade pre-invasive lesions in subjects exposed to asbestos as compared to nonexposed subjects (13\% versus 3\%). Moreover, a significant positive dose-effect relationship was found with duration of asbestos exposure as well as a negative relationship with delay since last exposure.

Until the late eighties, most peripheral adenocarcinomas were considered to be related to asbestos exposure [20]. This peripheral location was attributed to the preferential peripheral deposition of asbestos fibres [21], as well as the role of an asbestos related pulmonary fibrosis [22]. It suggested that systematic fibreoptic bronchial exploration may be less useful to detect these occupational tumours than those occurring in heavy smokers. However, the Carotene and Retinol Efficacy Trial (CARET) [23] found that the histological type of lung cancer did not differ in subjects exposed to asbestos as compared to the nonoccupationally exposed heavy smokers. Moreover, using analytical electronic microscopy from human bronchial microdissected material, CHURG [24] found that deposition of asbestos fibres in the airway mucosa could be estimated at $10-50 \%$ of the local parenchymal particle concentration. Thus, the carcinogenicity of asbestos for the proximal bronchial tree could be a consequence of the well known tobacco-asbestos interactions leading to a potentiation of the effect of asbestos exposure on the risk of developing preinvasive lesions [20]. However, as multivariate analysis showed an independent and statistically significant association between asbestos exposure and the presence of high grade pre-invasive bronchial lesions upon controlling for smoking, a direct action of asbestos fibres on the proximal bronchi cannot be excluded. To test this hypothesis, fibrosis signs on chest radiographs and CT scan were retrospectively looked for in subjects included in this study with high grade preinvasive lesions. No evidence of pulmonary fibrosis was found in these patients. This supports the asbestosrelated lung cancer hypothesis rather than the fibrosisrelated lung cancer hypothesis.

Less common occupational lung carcinogens have been described [17]. The present study indicates that these agents are also independently associated with the presence of proximal high grade pre-invasive lesions of the airways. These findings underscore the need for a more systematic assessment of exposure to these agents in risk evaluation studies of lung cancer.

The prevalence of high grade pre-invasive lesions found in this study was 33\% among subjects with synchronous lung cancer and 6\% among subjects without any personal history of lung cancer. The presence of synchronous high grade pre-invasive lesions in the bronchial tree of smokers having died of lung cancer or other causes has been known since the autopsy studies of AUERBACH et al. [25]. However, to the best of the authors' knowledge, the present study provides the first evidence that the presence of synchronous invasive bronchial lesions is significantly associated with that of high grade bronchial preinvasive lesions, upon controlling for smoking status and occupational carcinogens exposure, showing that the association of precancerous lesions and synchronous invasive cancers is not related to the difference between active smoking and exsmoking patients or asbestos exposure. The occurrence of multiple synchronous lung tumours is usually explained by a 
field cancerisation effect linked to the exposure of the whole mucosa to the same amount of carcinogens [26], associated with multiple genetic mutations at dispersed sites in the bronchial tree [27]. This is further suggested by the finding in this study that previous ENT cancer history was associated with the presence of high grade pre-invasive lesions. However, the independent associations of synchronous invasive lung cancer and carcinogen exposure with the presence of high grade pre-invasive bronchial lesions suggest other hypotheses such as increased genetic susceptibility to carcinogens, production of growth factors by the invasive tumour or the host and clonal expansion of a single mutation in the bronchial epithelium as reported by FRANKLIN et al. [28]. This finding as well as a recent report of multiple high grade pre-invasive lesions [5] should prompt more research on such mechanisms.

In the current study, the prevalence of high grade pre-invasive lesions was lower in subjects that had stopped smoking for $>1 \mathrm{yr}$ before the endoscopic exploration, suggesting a promotor activity of tobacco smoke on the transformed bronchial epithelium. This finding is in accordance with previous epidemiological studies showing a decrease of lung cancer risk with the length of smoking cessation in exsmokers [29], a lower prevalence of high grade lesions in former smokers relative to current smokers [30] and regression of high grade pre-invasive lesions after smoking decrease [31]. However, a recent study of pre-invasive lesions detected by autofluorescence bronchoscopy by LAM et al. [19] did not find a significant association between the presence of high grade pre-invasive lesions and smoking cessation. This discrepancy could be linked to a difference in the definition of high grade preinvasive lesions, as LAM et al. [19] included moderate dysplasia as well as severe dysplasia and CIS in high grade pre-invasive lesions.

Several potential limitations of the current study should be considered. First, moderate dysplasia was not included among high grade lesions because it has been shown to spontaneously regress much more frequently than severe dysplasia and CIS [6]. Consequently, the number of individuals with high grade pre-invasive lesions was relatively small $(n=21)$, suggesting that the results should be confirmed with larger studies. However, the associations between the presence of high grade lesions and smoking status, asbestos and nonasbestos occupational exposure, as well as the dose-effect relationship with duration of asbestos exposure remained significant when subjects with either cured or synchronous lung cancer or both were excluded (data not shown). Moreover, the association between the presence of high grade preinvasive lesions and synchronous lung cancer as well as smoking status and asbestos exposure remained significant when moderate dysplasia was included among high grade lesions.

Secondly, because of the invasiveness of the endoscopy procedure, leading to a narrow selection of high-risk subjects, the population may differ from the series usually described in the literature and the results may only apply to high-risk subjects. Furthermore, the study included very few nonsmokers $(n=13)$, limiting the ability to assess tobacco-related risk.

Thirdly, the findings only apply to pre-invasive lesions preceding squamous cell bronchial carcinoma occurring in the accessible proximal bronchial tree.

Fourthly, fluorescence endoscopy may not allow an exhaustive detection of pre-invasive lesions of the proximal bronchial tree. However, all previous studies [7-12] but one [32] strongly support an increased sensitivity of fluorescence endoscopy relative to white light endoscopy. As $>6$ sites per patient were biopsied on average, the authors are confident that only a small proportion of high-grade bronchial pre-invasive lesions was missed in this study.

Fifthly, the data are cross-sectional and do not offer proof that exposures found to be associated with high grade lesions are risk factors. While it seems highly likely that active smoking and occupational exposure preceded the occurrence of high grade lesions and are actual risk factors, it is unclear whether synchronous invasive cancer is a risk factor for high grade preinvasive lesions or whether they both originate from a common carcinogenic process as discussed above.

Despite these potential limitations, the authors believe that the data presented here may have a significant impact on management of patients at high risk of lung cancer. This study demonstrates that occupational exposure to respiratory carcinogens and particularly asbestos fibres is independently associated with the presence of high grade pre-invasive lesions of the proximal bronchus and confirmed that active smoking is independently associated with the presence of these lesions. These early precancerous or intraepithelial cancerous lesions are accessible to diagnosis using recent endoscopic procedures such as fluorescence endoscopy. The authors recently showed that $87 \%$ of carcinoma in situ and $37 \%$ of severe dysplasia remain high grade lesions or more at 2 yrs [6]. However, it is clear that a systematic endoscopy programme to detect these lesions would require very large resources, implying that the target population should be narrowed to a very high risk, well defined population. Given their high prevalence of high grade pre-invasive lesions and corresponding predicted probabilities, active smokers exposed to occupational respiratory carcinogens and patients with recently resected invasive lung cancer may represent a population of choice for such programmes. Further studies would also be needed to determine if early intervention such as systemic chemoprevention or conservative endobronchial treatment of high grade intra-epithelial lesions have a significant impact on survival in this selected population.

\footnotetext{
Acknowledgement. The authors thank R. Medeiros for his valuable advice in editing this manuscript.
}

\section{References}

1. Skuladottir H, Olsen JH. Epidemiology of lung cancer. Eur Respir Mon 2001; 17: 1-12. 
2. Midthun DE, Jett JR. Screening for lung cancer. Eur Resp Mon 2001; 17: 71-85.

3. Fontana RS, Sanderson DR, Woolner LB, Taylor WF, Miller WE, Muhm JR. Lung cancer screening: the Mayo Program. J Occup Med 1986; 28: 746-750.

4. Saccomanno G, Archer VE, Auerbach O, Saunders RP, Brennan LM. Development of carcinoma of the lung as reflected in exfoliated cells. Cancer 1974; 33: 256-270.

5. Venmans BJ, van Boxem TJ, Smit EF, Postmus PE, Sutedja TG. Outcome of bronchial carcinoma in situ. Chest 2000; 117: 1572-1576.

6. Bota S, Auliac JB, Paris C, et al. Follow-up of bronchial precancerous lesions and carcinoma in situ using fluorescence endoscopy. Am J Respir Crit Care Med 2001; 164: 1688-1693.

7. Lam S, MacAulay C, Hung J, LeRiche J, Profio EA, Palcic B. Detection of dysplasia and carcinoma in situ with a lung imaging fluorescence endoscope device. J Thorac Cardiovasc Surg 1993; 105: 1035-1040.

8. Thiberville L, Calduk H, Metayer J, Dominique S, Labbé D, Nouvet G. Autofluorescence versus white light endoscopy: Improvement in preinvasive lesions detection and false positive images (abstract). Eur Respir J 1996; 9: S23.

9. Lam S, Kennedy T, Unger M, et al. Localization of bronchial intraepithelial neoplastic lesions by fluorescence bronchoscopy. Chest 1998; 113: 686-702.

10. Venmans BJ, Van der Linden $H$, Van Boxem $T$, Postmus P, Smit E, Sujedja T. Early detection of preinvasive lesions in high risk patients. A comparison of conventional flexible and fluorescence bronchoscopy. J Bronchology 1998; 5: 280-283.

11. Hirsch FR, Prindiville SA, Miller YE, et al. Fluorescence versus white-light bronchoscopy for detection of preneoplastic lesions: a randomized study. J Natl Cancer Inst 2001; 93: 1385-1392.

12. Kennedy TC, Miller Y, Prindiville S. Screening for lung cancer revisited and the role of sputum cytology and fluorescence bronchoscopy in a high-risk group. Chest 2000; 117: Suppl. 1, 72-79.

13. Battey JF, Brown PH, Gritz ER, et al. Primary and secondary prevention of lung cancer: an international association for the study of the lung cancer workshop. Lung Cancer 1995; 12: 91-103.

14. WHO. Histological typing of lung and pleural tumours with contributions by pathologists from 14 countries. Travis WD, Colby TV, Corrin B, Shimosato Y, Brambilla E, eds. World Health Organization International Histological Classification of Tumors, XIII, 3rd Edn. Berlin/Heidelberg, Springer-Verlag, 1999.

15. Iwatsubo $\mathrm{Y}$, Pairon JC, Boutin $\mathrm{C}$, et al. Pleural mesothelioma: Dose-response relationship at low levels of asbestos exposure in a French populationbased case-control study. Am J Epidemiol 1998; 148: 133-142.

16. Orlowski E, Creau Y, Gauducheau E, et al. Evalutil: data base for assessing asbestos exposure among users of asbestos containing materials. Cahiers de Notes Documentaires 1997; 166: 5-16.

17. International Agency for Research on Cancer.
Overall evaluations of carcinogenicity to humans as evaluated in IARC Monographs Volumes 1-81. http:// 193.51.164.11/monoeval.ctrhall.html. Date updated: 22 August 2000; Date accessed: 1 September 2001.

18. Auerbach O, Stout AP, Hammond EC, Garfinkel L. Changes in bronchial epithelium in relation to smoking and in relation to lung cancer. $N$ Engl J Med 1961; 265: 253-268.

19. Lam S, leRiche JC, Zheng Y, et al. Sex-related differences in bronchial epithelial changes associated with tobacco smoking. J Natl Cancer Inst 1999; 91: 691-696.

20. Hillerdal G, Henderson DW, Path MRC. Asbestos, asbestosis, pleural plaques and lung cancer. Scand J Environ Health 1997; 23: 93-103.

21. Sebastien P, Fondimare A, Bignon J, Monchaux G, Desbordes J, Bonnaud G. Topographic distribution of asbestos fibers in human lung in relation to occupational and non-occupational exposure. In: Walton WH, McGoverd B, eds. Inhaled Particles Vol. IV. New York, Pergamon Press, 1977; pp. 435-444.

22. Whitwell F, Newhouse ML, Bennett DR. A study of the histological cell types in workers suffering from asbestosis in the United Kingdom. Br J Ind Med 1974; 31: 298-303.

23. Brodkin CA, McCullough J, Stover B, et al. Lobe of origin and histologic type of lung cancer associated with asbestos exposure in the carotene and retinol efficacy trial (CARET). Am J Ind Med 1997; 32: 582-591.

24. Churg A. The uptake of mineral particles by pulmonary epithelial cells. Am J Resp Crit Care Med 1996; 154: 1124-1140.

25. Auerbach O, Hammond EC, Garkinkel L. Changes in bronchial epithelium in relation to smoking: 1955-1960 versus 1970-1977. N Engl J Med 1979; 300: 381-385.

26. Slaughter DP, Southwick HW, Smejkal W. Field cancerization in oral stratified squamous epithelium: Clinical implication of multicentric origin. Cancer 1954; 6: 963-968.

27. Mitsudomi T, Yatabe $\mathrm{Y}$, Koshikawa $\mathrm{T}$, et al. Mutations of the p53 tumor suppressor gene as clonal marker for multiple primary lung cancer. J Thorac Cardiovasc Surg 1997; 114: 354-360.

28. Franklin WA, Gazdar AF, Haney J, et al. Widely dispersed p53 mutation in respiratory epithelium. A novel mechanism for field cancerization. $J$ Clin Invest 1997; 100: 2133-2137.

29. Peto R, Darby S, Deo H, Silcocks P, Whitley E, Doll R. Smoking, smoking cessation, and lung cancer in the UK since 1950: combination of national statistics with two case-control studies. Br Med J 2000; 321: 323-329.

30. Auerbach O, Stout AP, Hammond EC, Garfinkel L. Bronchial epithelium in former smokers. $N$ Engl J Med 1962; 267: 119-125.

31. Auer G, Ono J, Nasiell M, et al. Reversibility of bronchial cell atypia. Cancer Res 1982; 42: 4241-4247.

32. Kurie JM, Lee JS, Morice RC, et al. Autofluorescence bronchoscopy in the detection of squamous metaplasia and dysplasia in current and former smokers. $J$ Natl Cancer Ins 1998; 90: 991-995. 